\title{
Flashboiling-induced targeting changes in gasoline direct injection sprays
}

International J of Engine Research 2016, Vol. 17(I) 97-107 (c) IMechE 2015 DOI: $10.1177 / 1468087415604763$ jer.sagepub.com

\author{
Martin Krämer', Eberhard Kull' and Michael Wensing ${ }^{2}$
}

\begin{abstract}
By definition, flashboiling is referred to as superheated injections. The sudden occurrence of boiling inside the fuel can change the spray structure dramatically. Up to $99 \%$ of all injection processes during the New European Driving Cycle and 95\% during 'Real Driving Emissions' tests are, with respect to mid-range cars, in a state of thermodynamic nonequilibrium below the specific vapor pressure of gasoline. Considering this fact, the scientific question is not the appearance of flashboiling during the operation of stoichiometric homogeneous charge direct injection gasoline engines but the intensity of occurring spray processes and their influence on nominal spray designs. As a consequence of induced targeting changes, the positive influence of flashboiling on the droplet size distribution and the penetration depth can be counteracted. As main driving factors for targeting changes, jet-to-jet interactions can be identified. By applying appropriate nozzle design features, the potential of flashboiling can be exploited and the targeting changes of the nominal spray designs, considered negatively, are avoided mostly. This work focuses on flashboiling-induced targeting changes, the socalled phenomenon of "spray collapse": its root cause, development and avoidance.
\end{abstract}

\section{Keywords \\ Flashboiling, superheating, spray collapse, targeting changes, multihole injector, gasoline direct injection}

Date received: 2 June 20I5; accepted: 13 August 2015

\section{Introduction}

Modern concepts of downsized direct injection (DI) gasoline engines are predominantly operated in stoichiometric homogeneous combustion mode to meet the emission targets.

Independent of the engine operating mode, the strategic focus of the current research activities is a precise spray characterization at different boundary conditions and application strategies by means of appropriate diagnostics. Especially for DI engines, the spray characteristics are known to be one of the key factors to avoid abnormal combustion, particulate and hydrocarbon (HC) emissions as well as oil dilution due to wall wetting mechanism. ${ }^{1-6}$ The shape of the spray in the combustion chamber thereby plays a crucial role. The spatial orientation of the spray in the cylinder, called spray targeting, has the main objective to ensure the proper fuel distribution for mixture formation over the entire range of engine operating conditions. The targeting is specified by coordinates for each single jet of a multihole spray.

To achieve mixture homogeneity, early start of injection (SOI) timings during the intake stroke of the engine are advantageous. Due to the reduced distance between the piston and injector, the gasoline spray has only a low free penetration length and hence radial fuel distribution. Consequently, the particulate emissions at early SOI timings are driven by locally concentrated piston wetting. The increase in particles at late SOI timings is dominated by mixture inhomogeneities due to reduced time for mixture formation and tip sooting. Characteristically, the particle number (PN) emissions as a function of SOI timings show a "bathtub"-shaped behavior. ${ }^{7-10}$

As a consequence of the increased vapor pressure, high-volatility fuels show a more significant dependency on the ambient conditions, SOI and thus the engine operating conditions. ${ }^{11}$ Due to the throttling of the intake air during part load and idle operating, the in-cylinder pressure is subatmospheric. The expansion of the fuel below its specific saturation pressure results

\footnotetext{
'Continental Automotive GmbH, Regensburg, Germany

${ }^{2}$ Lehrstuhl für Technische Thermodynamik (LTT), Erlangen Graduate School in Advanced Optical Technologies (SAOT), Friedrich-Alexander Universität Erlangen-Nürnberg, Erlangen, Germany
}

\section{Corresponding author:}

Martin Krämer, Continental Automotive GmbH, Siemensstr. I2, D-93055 Regensburg, Germany.

Email: Martin.Kraemer@continental-corporation.com 


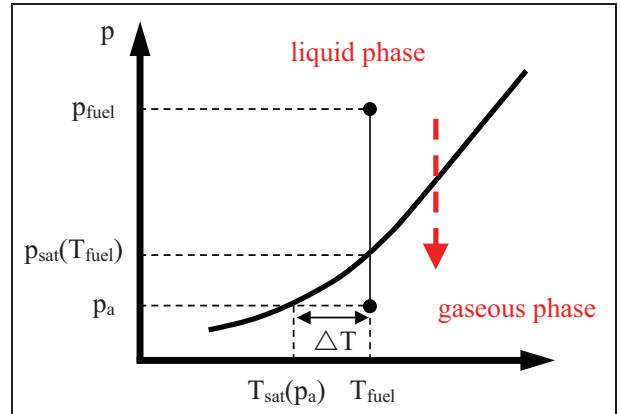

Figure I. Flashboiling parameter, according to Kamoun et al. ${ }^{17}$

in an abrupt atomization and evaporation of the liquid. The relevance of the so-called superheated injection events ("flashboiling") in gasoline applications is proven by use of optically accessible aggregates. ${ }^{12}$ The initialized spray processes can lead to a contracted spray targeting and thereby cause a locally focused mass distribution. The spray collapse is a well-known phenomenon to appear at gasoline direct injection (GDI) applications. ${ }^{13-15}$

Especially at subatmospheric operating conditions, the occurring spray processes that cause the phenomenon of spray collapse are not yet sufficiently understood. Based on the analysis of superheated spray characteristics, nozzle design features and application strategies to influence and avoid negative targeting changes are identified and discussed in this article.

\section{Flashboiling}

Flashboiling (superheated injection) occurs by rapidly depressurizing a liquid below its specific saturation pressure $^{16}$ (see Figure 1).

Due to the expansion from fuel pressure to ambient backpressure, the boiling curve is crossed and the fluid is in a thermodynamic non-equilibrium characterized by an excess of intrinsic energy. This metastable state is called superheated. If the internal energy cannot be dissipated at sufficiently high evaporating rate from the surface to achieve thermodynamic equilibrium, phase transition is occurring inside the liquid. ${ }^{17}$

The temporal development and the timing of the phase transition are dominated by the level of superheating. Generally, superheating can be described by pressure or temperature dependencies (compare Figure 1). Based on the comparison of characteristic numbers commonly used, the level of superheating inside this study is described as the ratio between backpressure and vapor pressure $\left(\mathrm{p}_{\mathrm{a}} / \mathrm{p}_{\mathrm{sat}}\right)$. By definition, for values of $\mathrm{p}_{\mathrm{a}} / \mathrm{p}_{\text {sat }}<1$, the fluid is superheated, while the ratio decreases with increasing level of superheating.

Flashboiling can be divided into three process steps; the nomenclature may vary: ${ }^{18,19}$

1. Nucleation

2. Bubble growth

3. Breakup/atomization.
1. The nucleation of vapor bubbles can occur homogeneously or heterogeneously. Homogeneous nucleation is driven statistically without the presence of impurities inside the fluid, ${ }^{20}$ preferentially at high-volatile liquids ${ }^{21}$ and high level of superheating. ${ }^{22}$ Based on a turbulent two-phase flow for gasoline DI sprays, the technical relevance of a homogeneous fluid can be regarded as inferior. ${ }^{23}$ The heterogeneous nucleation occurs at already existing phase boundaries inside the fluid. It depends on the boundary conditions defined by temperature and pressure as well as the geometrical design of the hydraulic system. Disturbances inside the flow can initiate the nucleation process and therefore the flashboiling of the superheated liquid. ${ }^{24}$ All kinds of cavitation and turbulence generation, impurities in form of particulates and dissolved gases inside the liquid are of technical relevance.

2. After the nucleation process, the nuclei or microbubbles are growing against the forces of surface tension, viscosity and inertia of the surrounding liquid phase. Dominating growth mechanisms are the displacement of the liquid due to the excess pressure inside the bubble depending on superheating and the volumetric expansion related to evaporation processes. For detailed information and numerical approaches, see Ashgriz, ${ }^{25}$ Miyatake et al. ${ }^{26}$ and Plesset and Prosperetti. ${ }^{27}$

3. In direct analogy to cavitation, ${ }^{28}$ pressure pulsations inside the spray can cause the disruption (implosion) of the bubbles and initiate the atomization process. Basically, the thermodynamic nucleation, however, should not be mixed up with hydrodynamic formation mechanisms of cavitation.

Due to the thermodynamic shattering of the liquid jet, very high atomization levels result for superheated injections. ${ }^{29-32}$ The Sauter mean diameter can be described as a function of superheating. ${ }^{33}$ Engine results show a positive influence of the increased atomization and superheated evaporation on particulate emissions. ${ }^{34}$ Concept studies confirm these influences for gasoline DI sprays up to supercritical conditions by additional conditioning of the fuel with external heating systems. ${ }^{35}$

Nevertheless, these positive benefits due to superheating of the fuel can only be achieved by appropriate nozzle designs and application strategies to avoid negative targeting changes and therefore locally concentrated mass distributions inside gasoline sprays.

\section{Thermodynamic background}

Fluid-specific fuel properties are the main factors to influence superheated injections. Commercial gasoline consists of more than 300 HCs dominated by alkanes and aromates with a boiling temperature ranging from 


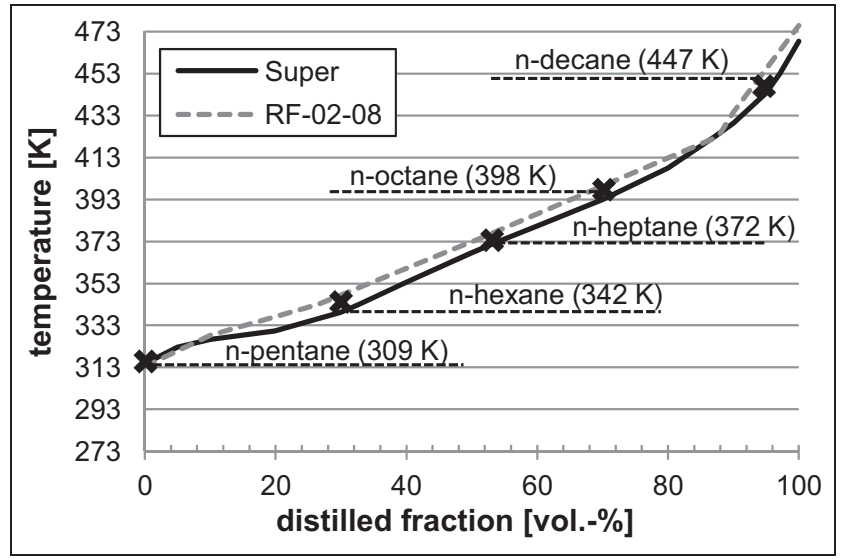

Figure 2. Distillation curves RF-02-08, premium gasoline.

303 to $473 \mathrm{~K}$. Figure 2 shows measured distillation curves of EU-5 certificated Coordinating European Council (CEC) legislative fuel (RF-02-08) and commercial premium gasoline (Super), according to DIN EN ISO $3405 .^{36,37}$

The distillation range of gasoline can be approximated by $\mathrm{C} 5-\mathrm{C} 11$ alkanes. The boiling points of selected single-component fuels for subsequent studies are marked.

In subatmospheric conditions, the saturation pressure is dominating the spray propagation processes. The vapor pressure is a fluid-specific characteristic and only temperature dependent. From physical point of view, the vapor pressure curve separates the phase transition between liquid and gaseous phases. Figure 3 displays measured vapor pressure curves for RF-02-08 and the selected single-component fuels according to the standard test method for the determination of vapor pressure (ASTM D6378). The saturation pressure of RF-02-08 is significantly shifted toward high-volatile fuel components due to their elevated partial pressure in the multi-component fuel. Depending on the batch, type of oil, distillation process and the aging of the fuel, the vapor pressure might show large differences.

Based on the multi-component character of real gasoline, the vapor pressure curve cannot be seen as singlephase boundary for the entire fuel blend. High-volatility fuel fractions change into gaseous phase at more moderate conditions, for example, n-butane with a boiling point of $272-274 \mathrm{~K}\left(3 \mathrm{wt} \%\right.$ of premium gasoline $\left.{ }^{38}\right)$. The evaporation behavior of multi-component fuels is known to be distillation-like at moderate ambient conditions. $^{39}$ The phase transition of volatile components in binary mixtures always leads to a coexisting amount of the low volatility fraction in the gaseous phase. ${ }^{40}$ For this reason, even at atmospheric boundary conditions, a thermodynamic fractionation can occur, which does not only affect high-volatile components. ${ }^{41,42}$

Based on a load point calculation ${ }^{43}$ as well as experimental cylinder pressure and dynamic fuel temperature measurements for a representative mid-range vehicle $(1.4 \mathrm{~L}, 91 \mathrm{~kW})$, up to $99 \%$ of all injection processes

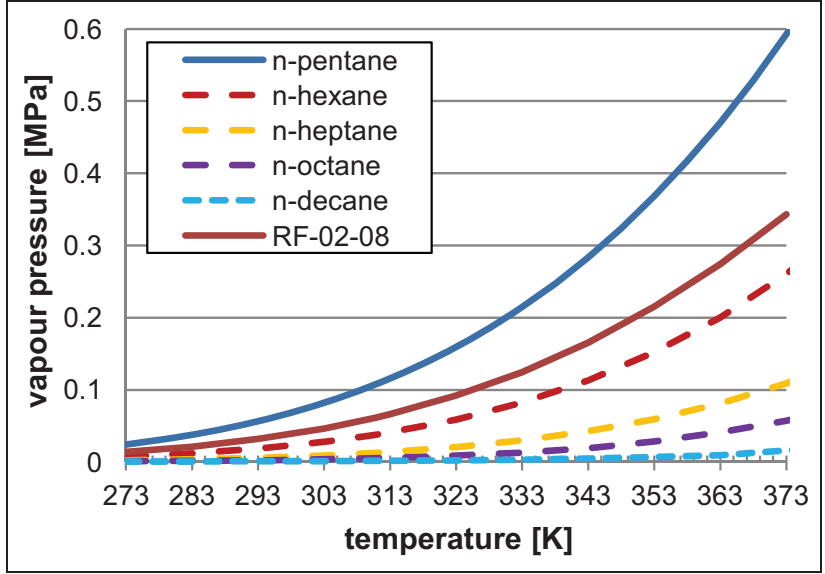

Figure 3. Vapor pressure curves: RF-02-08 and selected alkanes.

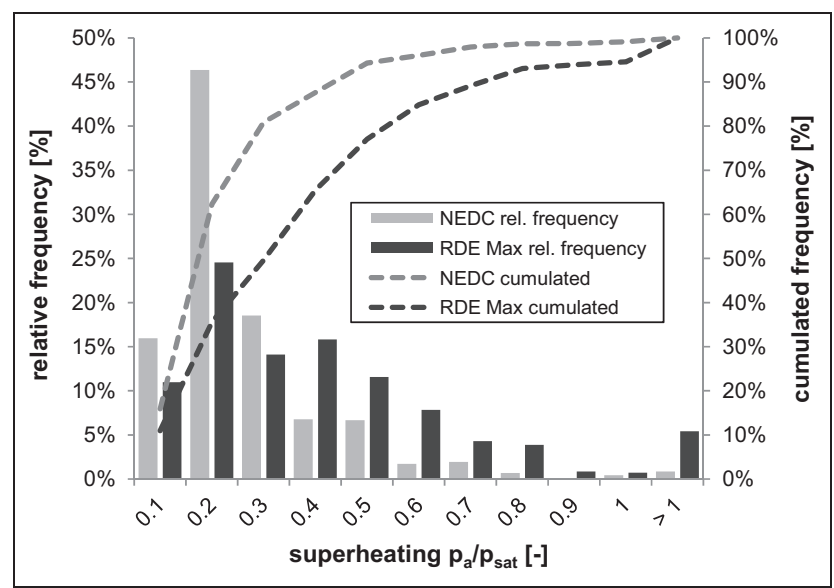

Figure 4. Flashboiling histogram NEDC/RDE Max; RF-02-08.

during the New European Driving Cycle (NEDC) and 95\% during 'Real Driving Emissions' (RDE) tests are in a state of thermodynamic non-equilibrium below the specific vapor pressure of gasoline (see Figure 4). Displayed is a load point histogram to identify the probability distribution of relevant superheating levels for the reference fuel RF-02-08. Dominant are superheating levels $\mathrm{p}_{\mathrm{a}} / \mathrm{p}_{\mathrm{sat}}<0.5$. For the calculation, only homogeneous injection events are considered. Stratified combustion mode during catalytic converter heating is not included due to a comparable low percentage within the driving cycles. The expansion of the engine operation map to higher effective mean pressures in future driving cycles only shows a limited influence on the percentage of flashboiling. The intensity of superheated spray processes, nevertheless, will be reduced.

Taking into account the multi-component character of gasoline, Figure 5 shows the superheating level for the exemplary selected alkanes during NEDC which is more critical for flashboiling. Superheating can be identified up to n-octane (boiling point $398 \mathrm{~K}$ ) with a cumulated percentage of $\sim 40 \%$ of all load points. Regarding 
n-pentane, n-hexane and n-heptane, representative for approximately $50 \%$ by volume of the fractions inside gasoline (compare Figure 2), the percentage of superheating is above $75 \%$. The chosen surrogate fuels form no azeotrope, nevertheless molecular interrelations among different fuel components in real gasoline lead to a more complex behavior.

The limitation of flashboiling to low part load and idle operation therefore is not reasonable. Generally, superheating of single-fuel components is relevant during the entire engine operation. In dependency of the superheating level, the intensity of superheated spray processes is, however, varying.

\section{Jet-to-jet interactions}

Generally, the terms and definitions of flashboiling and spray collapse, and targeting changes, respectively, have to be strictly separated. By definition, flashboiling is referred to as superheated injections, whereas spray collapse is referred to as the spatial contraction of nominal spray targetings of gasoline sprays. Spray collapse can be affected or induced by flashboiling, but also be enforced at non-superheated conditions by a simple

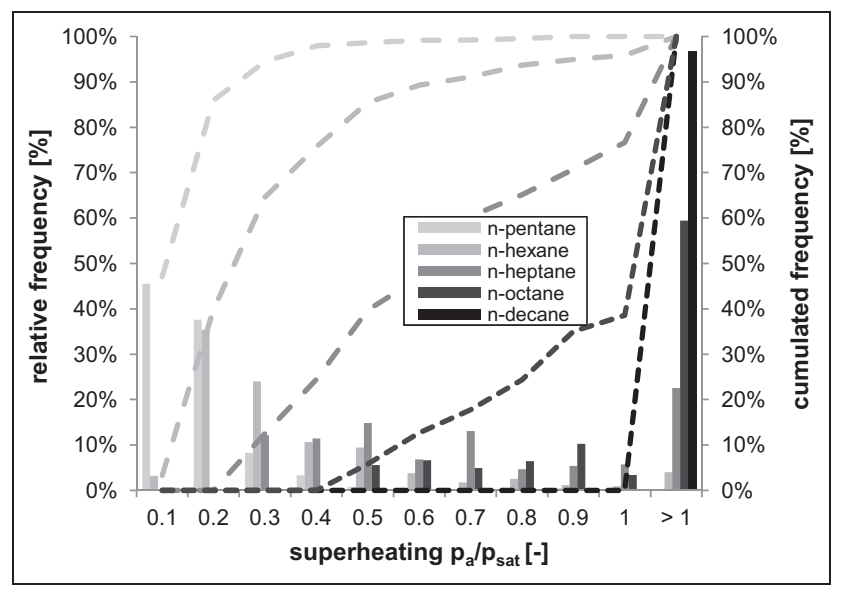

Figure 5. Flashboiling histogram NEDC; alkanes. increase in the flow hole number at multihole injectors (see Lenz ${ }^{44}$ and Khan et al. $^{45}$ ). From phenomenological point of view, very often no differentiation is made and spray collapse is equalized with flashboiling.

It is well proven that interactions between adjacent jets, called jet-to-jet interactions, affect changes in nominal spray targetings at superheated conditions. ${ }^{46-48}$ Due to the high amount of varying nozzle geometries, boundary conditions and experimental fluids in former studies, it is not possible to establish general geometrical correlations. For this reason, the following results are exemplary based on a three-hole solenoid-driven gasoline injector with drilled flow hole directions of $30^{\circ}$ height angle and jet spacing of $120^{\circ}$ in side angle. Due to the spatial separation, free optical access for singlejet evaluation is given without negative extinction of superimposed spray jets. By comparison with a symmetrical six-hole nozzle with identical spray hole design, geometrical correlations can be drawn. Spray momentum-based targetings of both nozzle configurations are visualized in Figure 6. The coloring displays the spatial momentum distribution over the cross section for each jet. The shown resolution of the polar grids is $20^{\circ}$ in side angle and $5^{\circ}$ in height angle.

The following experimental studies are carried out in a permanently scavenged injection chamber with full optical access. To display the entire range of flashboiling conditions relevant for homogeneous engine operation, the chamber can be evacuated down to $0.03 \mathrm{MPa}$ backpressure. An external heating system conditions the fuel and the injector valve housing on constant temperature levels to ensure comparable test conditions. Shadowgraphy imaging technique was applied to characterize flashboiling-induced targeting changes. The background illumination was realized by a Xenon flash in combination with a diffusion disk. Spray images are captured perpendicular to the measurement plane by a fast exposure charge-coupled device (CCD) camera (PCO SensiCam), using 12-bit grayscale, $1280 \times 1024$ pixels at a spatial resolution of 10 pixels $/ \mathrm{mm}$ inside the detection area. The temporal resolution with a minimum delay of $50 \mu \mathrm{s}$, between the sampling points in

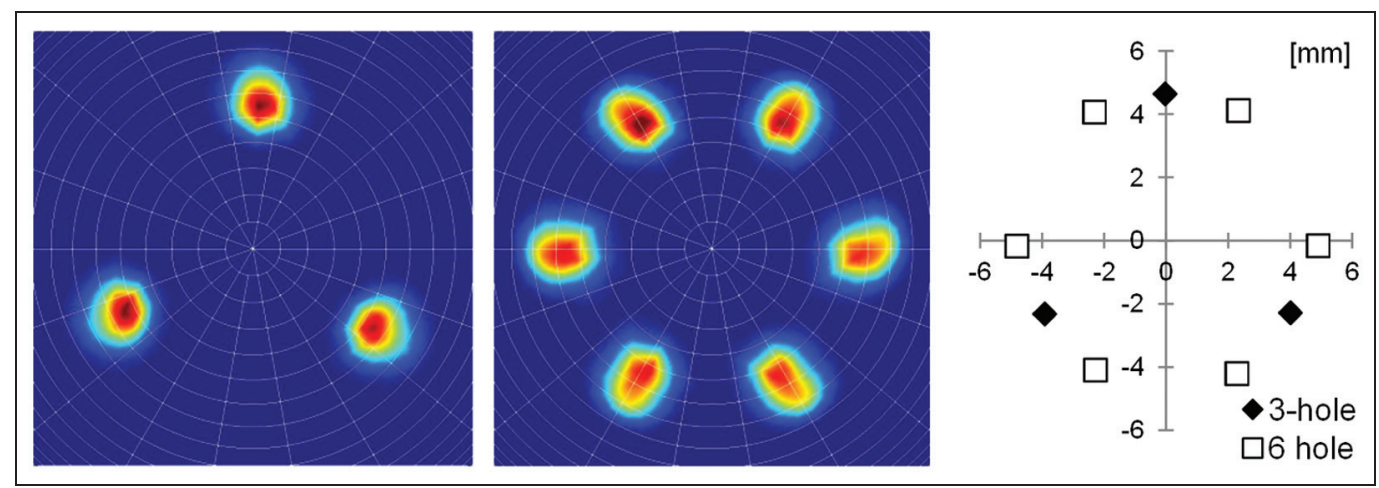

Figure 6. Spray momentum-based targetings in polar coordinates (left, middle); Cartesian projection (right); $10 \mathrm{~mm}$ distance to nozzle tip. 


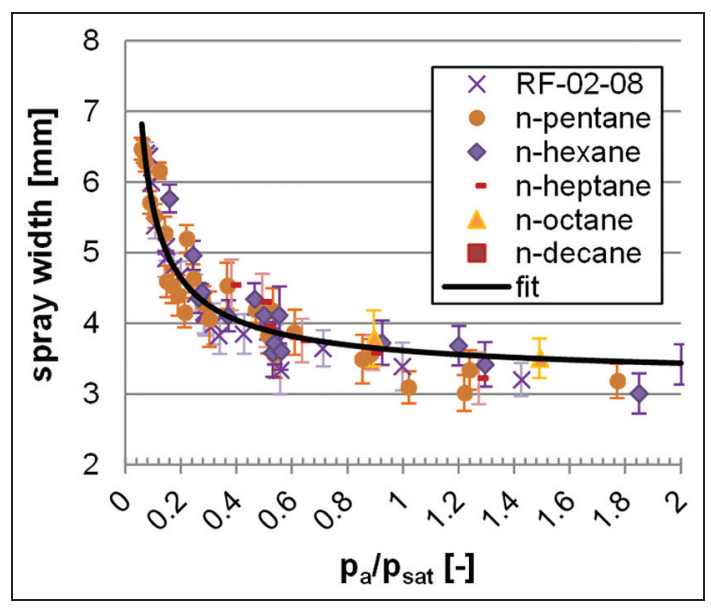

Figure 7. Spray width versus $\mathrm{p}_{\mathrm{a}} / \mathrm{p}_{\text {sat }}$; three-hole injector.

time, covers the entire injection process between $50 \mu \mathrm{s}$ and $3 \mathrm{~ms}$ after visible start of injection (vSOI). To ensure statistical accuracy, 15 images were sampled at each single time step. The spray visualization is done by false color-displayed average grayscale images. Additional information about the measurement setup and the image post processing algorithm can be viewed in Krämer et al. ${ }^{49}$

The systematic variation in backpressure (0.03-0.10 MPa) and fuel temperature (303-368 K) at $20 \mathrm{MPa}$ injection pressure covers engine-relevant operation conditions in a wide range. At 111 operation points, the parametric study displays identical boundary conditions as well as fluid-specific superheating levels for the reference gasoline RF-02-08 and the selected single-component alkanes. The characterization of the flashboiling behavior was done at $650 \mu \mathrm{s}$ after vSOI, to ensure the entire spray being inside the optical detection area of the spray chamber. This approach considers different time histories in spray collapse development and penetration as a result of varying temperature and pressure conditions, as well as different nozzle designs and fuel pressures. The characterization of the spray disintegration process was done by evaluating the spray widening orthogonally to the injector axis at $5 \mathrm{~mm}$ distance from the nozzle tip and an intensity-weighted opening angle of the spray. This angle equals the spray direction out of the single-jet evaluation, transferred to multihole sprays. The angular calculation is based on gray values, not the spray boundary. The exclusive evaluation of basic macroscopic spray parameters is used to emphasize fundamental geometrical correlations of jet-to-jet interactions.

\section{Three-hole injector}

Progressively with the superheating level of the fuel, the single plumes are widening from initially $3 \mathrm{~mm}$ spray width up to $6.5 \mathrm{~mm}$ (see Figure 7). The different fuels show identical superheating behavior in the range of the standard deviation. For driving cycle relevant

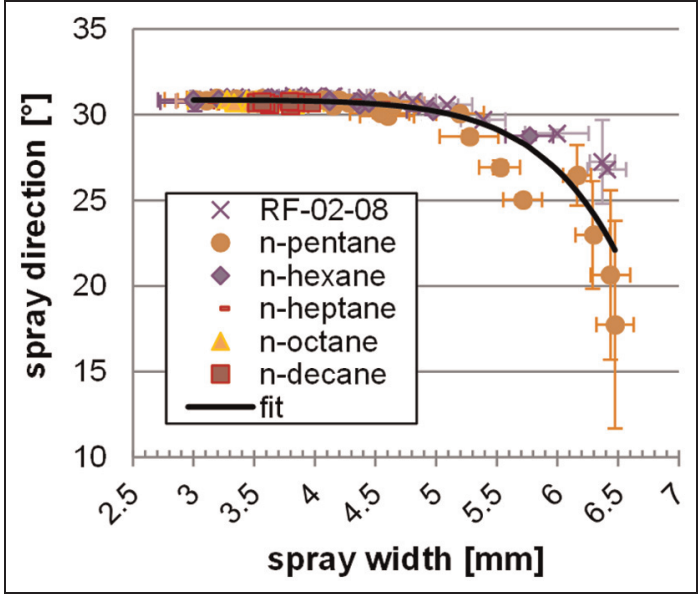

Figure 8. Spray direction versus spray width; three-hole injector.

operating conditions at $\mathrm{p}_{\mathrm{a}} / \mathrm{p}_{\mathrm{sat}}<0.5$, exponential jet widening can be identified. Up to a spray width of $5 \mathrm{~mm}$, the single-jet spray direction is stable (see Figure 8). Any further widening in the nozzle-near area causes interactions between the single jets and hence deflections toward the injector axis.

Figure 9 shows exemplary average images for the reference fuel RF-02-08 at $650 \mu$ s after vSOI. Clearly visible, the single jets are spatially separated at low superheating levels. Due to continuous widening, the jets start to interact in the nozzle-near spray area. Globally seen, the superheating-driven atomization causes a significant widening of the jets.

\section{Six-hole injector}

Basically, identical behavior can be identified for the six-hole injector. Due to superheating, the entire spray is widening in the nozzle-near area (see Figure 10). Instantaneously with the widening of the single jets, the intensity-weighted opening angle of the spray is reduced (see Figure 11). All measured operation conditions follow one common relationship.

Figure 12 shows representative average images of the six-hole injector with the reference fuel RF-02-08. The defined injector, and thus spray orientation, displays the maximum dimension for symmetrical hexagon targetings. With this approach, the maximum targeting changes can be detected. Already at moderate superheated conditions $\left(\mathrm{p}_{\mathrm{a}} / \mathrm{p}_{\text {sat }}=1.0\right)$, interactions can be identified in the nozzle-near area. The interaction areas increase with superheating until the targeting shows a locally focused spray structure.

In direct comparison with the three-hole injector, the six-hole targeting reacts more sensitive to the superheating of the fuel. Because of the increased number of flow holes, no radial expansion of the jets can occur without inducing dominant jet-to-jet interactions. Based on identical single-jet widening (equal spray hole design), the free jet-individual expansion space can be concluded as the main influencing factor. 


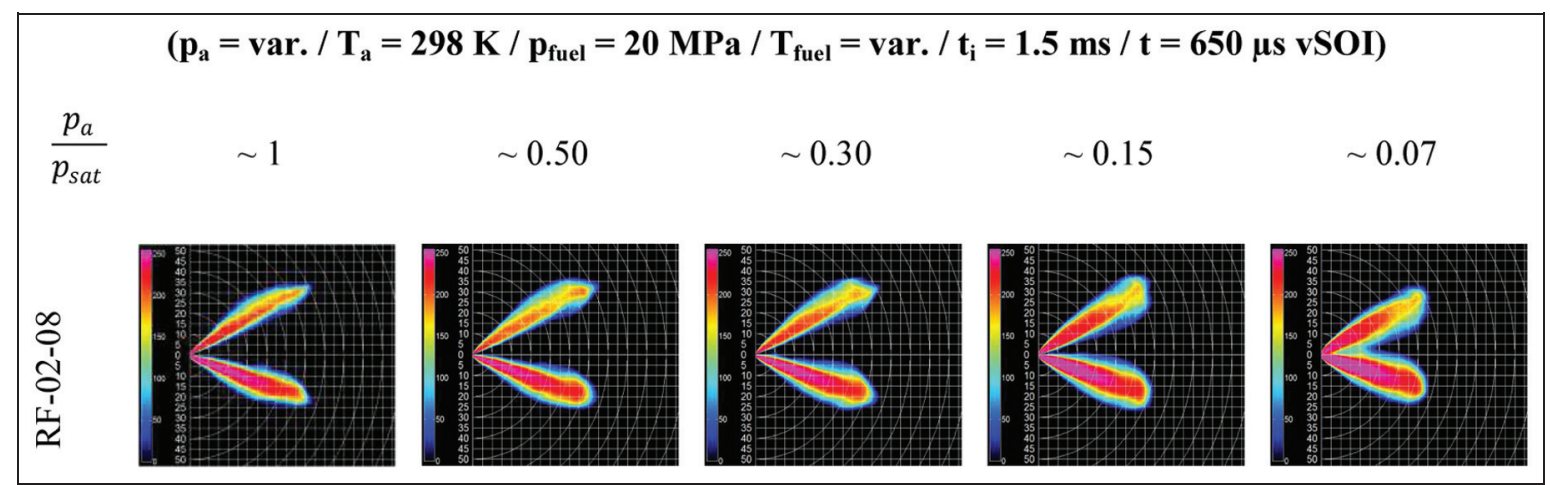

Figure 9. Three-hole injector, RF-02-08, shadowgraphy, averaged grayscale images displayed in false color.

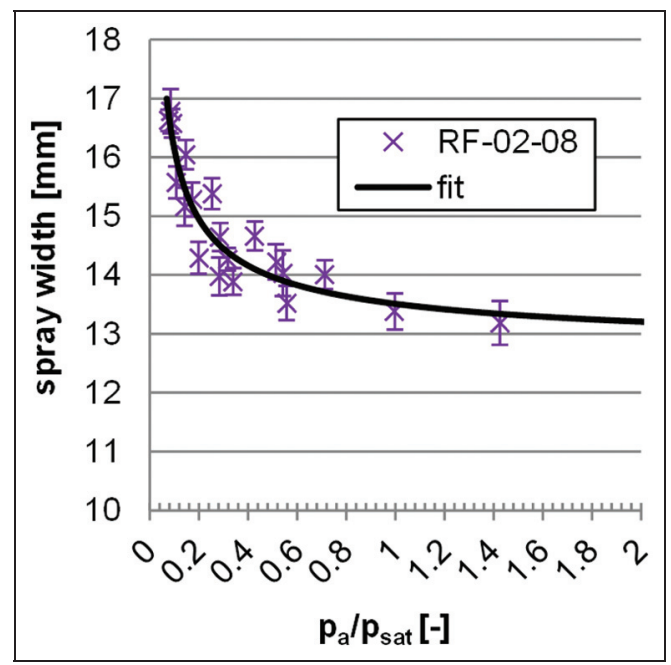

Figure 10. Spray width versus $\mathrm{Pa}_{\mathrm{a}} / \mathrm{P}_{\text {sat }}$; six-hole injector.

Due to the spatial spray hole orientation, this "space" is defined as solid angle between adjacent jets. Out of spray momentum measurements, the solid angles are determined to be $46.8^{\circ}$ for the three-hole injector and $27.5^{\circ}$ for the six-hole targeting. The resulting solid angle ratio of $\sim 3^{0.5}$ displays the additional available expansion space for the single jets of the three-hole injector. This factor can also be proven geometrically out of the edge length from symmetrical hexagons and equilateral triangles with circles circumscribed identically (see Figure 13).

Figure 14 displays the relative targeting change versus the spray widening as smoothing function for both nozzle configurations. In the range of the $95 \%$ confidence interval (CI), the three-hole injector shows a factor $\sim 3^{0.5}$ increased widening at identical contraction of the targeting. As conclusion, the spray collapse, or generally the change in targetings can be determined geometrically by knowledge of the single-jet behavior.

\section{Influencing factors}

Based on the physical basics of flashboiling and the geometrical determination of jet-to-jet interactions,

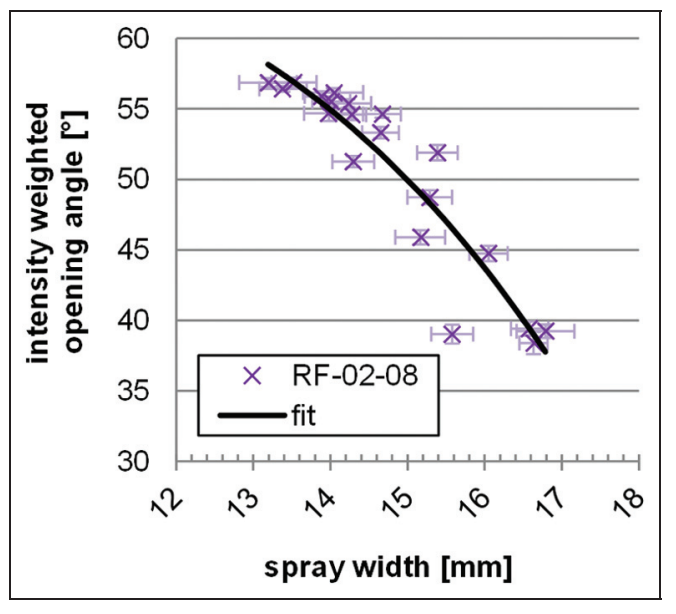

Figure II. Intensity-weighted opening angle versus spray width; six-hole injector.

Figure 15 displays a novel organizational chart for flashboiling-induced targeting changes with interrelations of relevant influencing factors.

In preliminary investigations, several design and application parameters have been studied on their conformity and sensitivity. The following result discussion includes a representative selection of influencing factors on flashboiling-induced targeting changes.

\section{Geometrical separation}

Spray targetings are typically adjusted to the geometrical layout of individual combustion chambers. In dependency of the flow hole number and the spray targeting, the free individual expansion space for single jets is varying. Via wide and narrow spray layouts for six-hole targetings, the influence of the geometrical jet separation is displayed representatively in Figure 16. Covering all operation points, the wide targeting is generally more stable compared to the narrow targeting, which can be referred to the geometrical dependency of jet-to-jet interactions. Sprays with a large jet-individual expansion space are generally more stable against targeting changes. The free jet-individual expansion space 


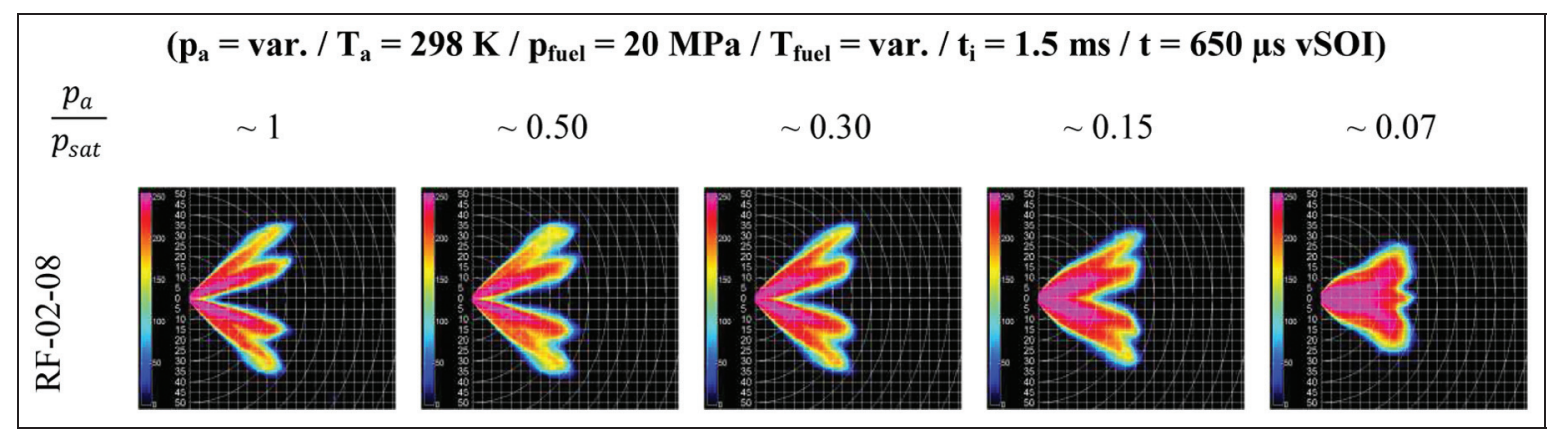

Figure I2. Six-hole injector, RF-02-08, shadowgraphy, averaged grayscale images displayed in false color.

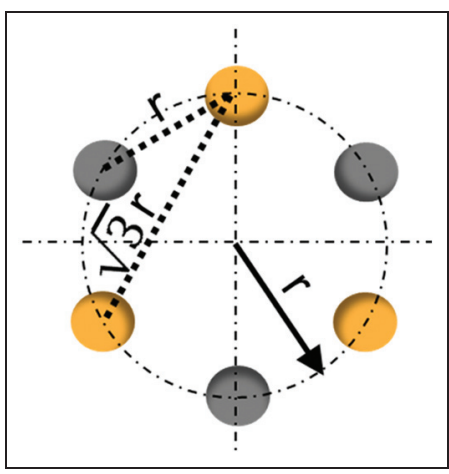

Figure 13. Geometrical jet distance.

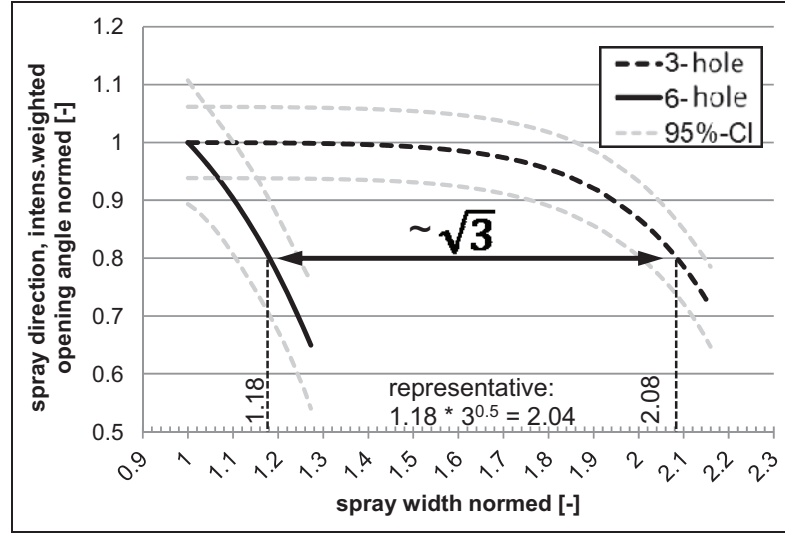

Figure 14. Spray collapse versus spray width, three-hole/sixhole injector, normed with $0.01 \mathrm{MPa} / 303 \mathrm{~K}$. dominates the intensity of jet-to-jet interactions. The presented results conform with former studies. ${ }^{50,51}$

\section{Fuel pressure variation}

Representatively, the fuel pressure influence is discussed for 7 and $20 \mathrm{MPa}$. The phenomenon of spray collapse is based on jet-to-jet interactions and accordingly induced flow fields. Basically, small and slow droplets are more affected by surrounding flow fields than droplets with high inertia and velocity. ${ }^{52}$ In first approximation, the droplet size distributions of both fuel pressures are comparable due to the dominant influence of flashboiling on the atomization. ${ }^{33}$ However, the droplet velocities and therefore the stability of the predefined jet direction are enhanced with the fuel pressure. For this reason, the separation of the single jets is more stable at $20 \mathrm{MPa}$ fuel pressure (see Figure 17). The influence of small and slow droplets by induced velocity fields causes the spray targeting to collapse for $7 \mathrm{MPa}$ injection pressure.

\section{Injection duration variation}

The phenomenon of spray collapse is a time-dependent process. Representatively at $0.05 \mathrm{MPa}$ backpressure and $20 \mathrm{MPa}$ injection pressure, three different injection durations are compared. Figure 18 displays the appropriate spray images. Noticeably, the frontal recirculation areas vanish for the long injection duration with

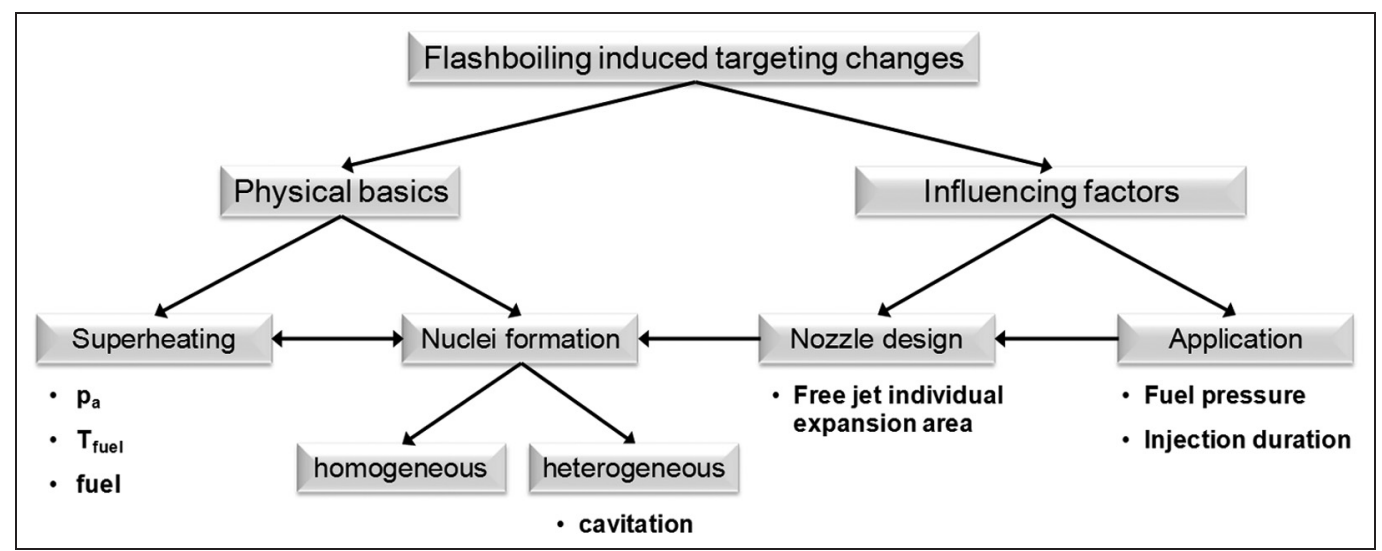

Figure I5. Flashboiling-induced targeting changes - organizational chart. 


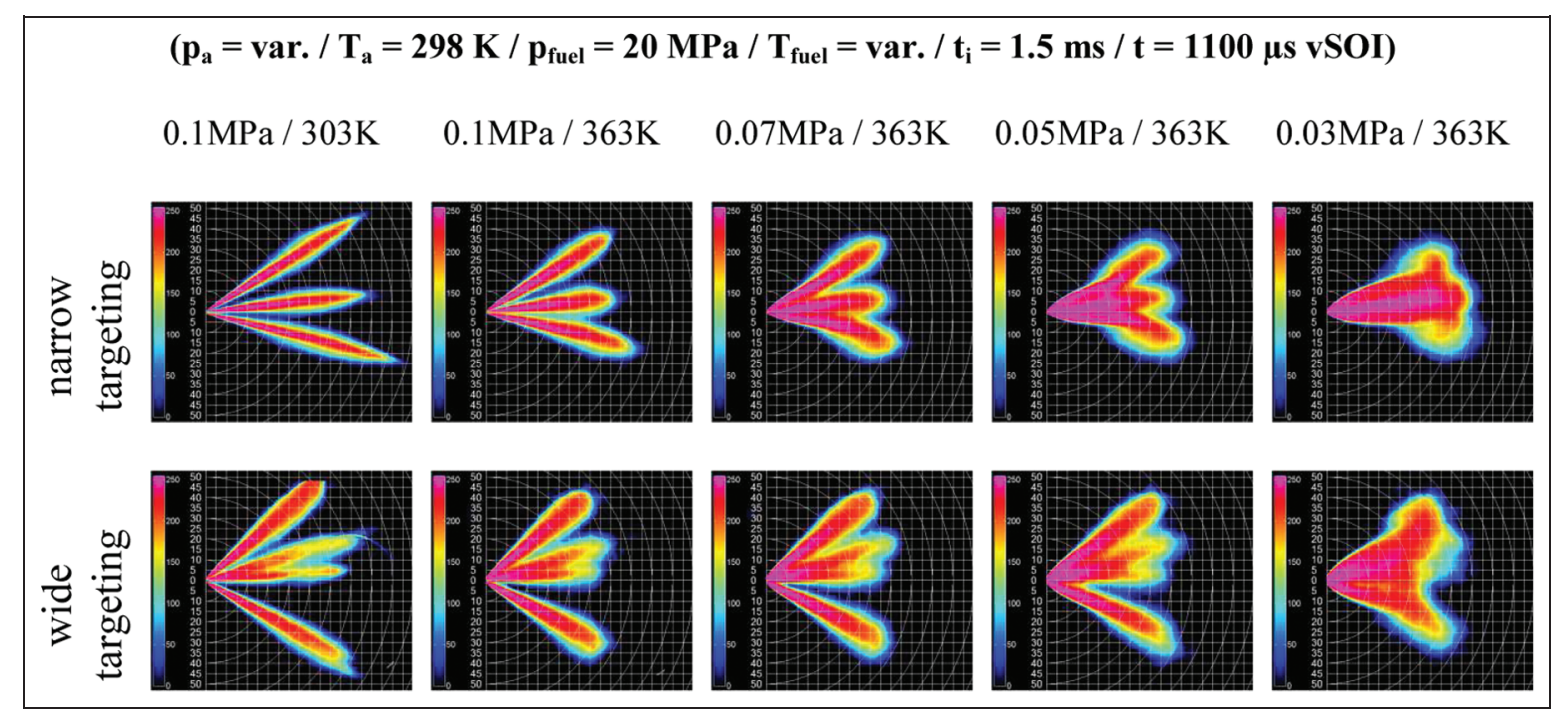

Figure 16. Flashboiling-induced targeting changes - geometrical separation, shadowgraphy; averaged grayscale images displayed in false color.

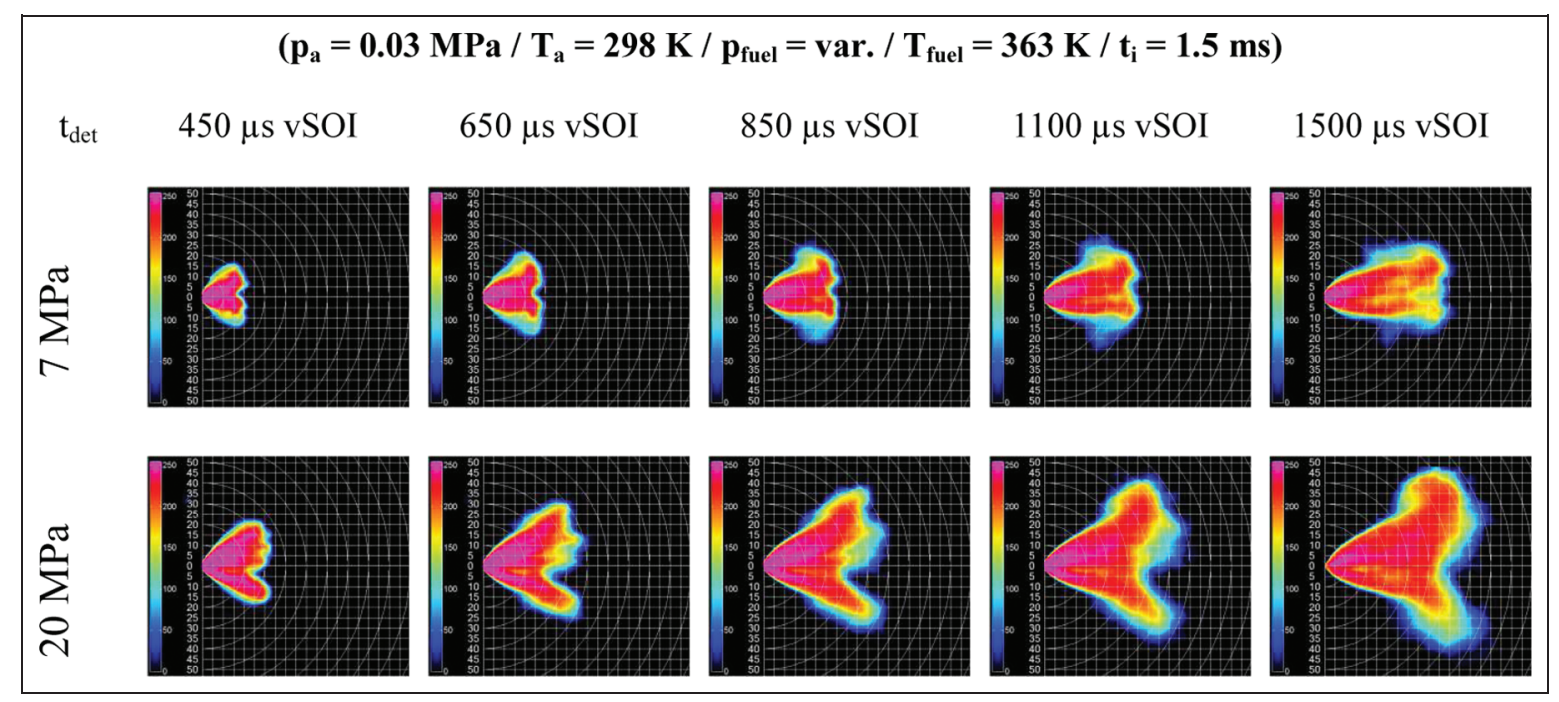

Figure 17. Flashboiling-induced targeting changes - fuel pressure influence, wide targeting, shadowgraphy; averaged grayscale images displayed in false color.

continuing spray contraction. At later points in time, the targeting is collapsed to a compact, single-jet-like spray structure. At shorter injection durations, the advancing contraction is visibly interrupted, in particular noticeable for the ballistic minimum injection quantity. Due to the short injection durations, induced flow fields and negative pressure regions have a shorter lifetime. For this reason, the follow-up behavior of small droplets and therefore the deflection of the single jets are interrupted, visible at the separable spray structure.

\section{Summary/conclusion}

This study investigated flashboiling-induced targeting changes, the so-called phenomenon of "spray collapse": its root cause, development and avoidance. The experimental results lead to the following conclusions:

1. Generally, the terms and definitions of flashboiling and spray collapse have to be strictly separated. By definition, flashboiling is referred to as superheated injections, whereas spray collapse is referred to as the contraction of nominal spray targetings of gasoline sprays. Spray collapse can be affected or induced by flashboiling but also be enforced at non-superheated conditions by a simple increase in the flow hole number at multihole injectors.

2. The superheating-driven atomization causes a significant widening of single jets.

3. Jet-to-jet interactions are identified as root cause for spray collapse. 


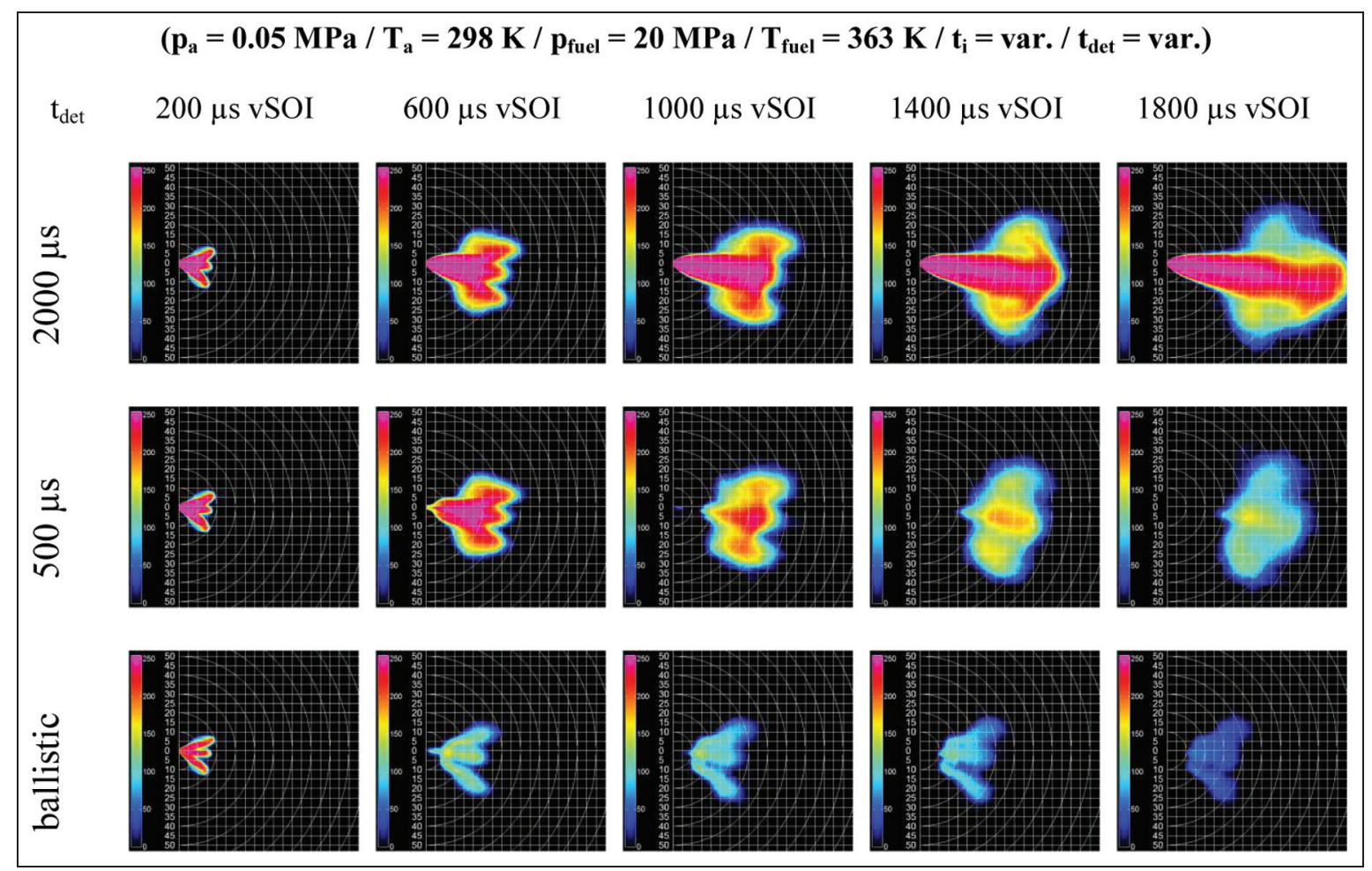

Figure I 8. Flashboiling-induced targeting changes - injection duration influence, shadowgraphy; averaged grayscale images displayed in false color.

4. In the range of the standard deviation, the widening of the single jets is independent of the fuel used; always observing at the same $\mathrm{p}_{\mathrm{a}} / \mathrm{p}_{\text {sat }}$. The vapor pressure and therefore the superheating levels are dominating the structure of flashboiling sprays. Naturally, the level of superheating changes for different fuel compositions even at constant operating conditions. Relevant differences can appear for various fuel sources, aging processes and so on; therefore, attention to flashboiling is required to ensure emission standards for different fuel qualities.

5. The spray collapse behavior can be determined geometrically by knowledge of the single-jet behavior at superheated conditions. Based on geometrical correlations, a global characterization or scaling of flashboiling via induced targeting changes only displays injector design individual phenomena in dependency of the superheating.

6. A novel organizational chart of influencing factors on flashboiling-induced targeting changes was presented.

7. By applying appropriate nozzle design features, the potential of flashboiling can be exploited and the targeting changes in the nominal spray designs, considered negatively, are avoided mostly.

\section{Declaration of conflicting interests}

The author(s) declared no potential conflicts of interest with respect to the research, authorship and/or publication of this article.

\section{Funding}

The author(s) received no financial support for the research, authorship and/or publication of this article.

\section{References}

1. Zhao FQ, Harrington DL and Lai MC. Automotive direct-injection gasoline engines. Warrendale, PA: Society of Automotive Engineers Press, 2002.

2. Birkigt A. Analyse von Vorentflammungsphänomenen an hoch aufgeladenen Ottomotoren mit Direkteinspritzung. $\mathrm{PhD}$ Dissertation, Technische Fakultät, Universität Erlangen-Nürnberg, Erlangen, 2012.

3. Serras-Pereira J, Aleiferis PG and Richardson D. Imaging and heat flux measurements of wall impinging sprays of hydrocarbons and alcohols in a direct-injection spark-ignition engine. Fuel 2012; 91(1): 264-297.

4. Chin ST and Lee CF. Numerical investigation of the effect of wall wetting on hydrocarbon emissions in engines. P Combust Inst 2002; 29(1): 767-773.

5. Price P. Direct injection gasoline engine particulate emissions. PhD Dissertation, University of Oxford; Ford Motor Co. Ltd, 2009.

6. Baecker H, Lerch J and Kroiss M. Untersuchungen zur Benzindirekteinspritzung vor dem Hintergrund zukünftiger Emissions- und Verbrauchsanforderungen. Essen: Haus der Technik, 2011.

7. Eichlseder H, Klüting M and Piock W. Grundlagen und Technologien des Ottomotors XIV (Der Fahrzeugantrieb). Wien: Springer-Verlag, 2008.

8. Price P, Twiney B, Stone R and Walmsley H. Particulate and hydrocarbon emissions from a spray guided direct injection spark ignition engine with oxygenate fuel blends. SAE technical paper 2007-01-0472, 2007. 
9. Mittal M, Hung D, Zhu G and Schock H. Fuel spray visualization and its impingement analysis on in-cylinder surfaces in a direct-injection spark-ignition engine. $J$ Visual 2011; 14(2): 149-160.

10. Köpple F, Jochmann P, Kufferath A and Bargende M. Investigation of the parameters influencing the spray-wall interaction in a GDI engine - prerequisite for the prediction of particulate emissions by numerical simulation. SAE Int J Engines 2013; 6(2): 911-925.

11. Sementa P, Vaglieco B and Catapano F. Thermodynamic and optical characterizations of a high performance GDI engine operating in homogeneous and stratified charge mixture conditions fueled with gasoline and bio-ethanol. Fuel 2012; 96: 204-219.

12. Pitcher G, Goodwin MS, Wigley G and Hethel N. Relationship between in-cylinder flow and pressure and GDI spray propagation. In: International symposium on applications of laser techniques to fluid mechanics, Libson, Portugal, 12-15 July 2004. The Calouste Gulbenkian Foundation.

13. Achleitner E, Bäcker $\mathrm{H}$ and Funaioli A. Direct injection systems for Otto engines. SAE technical paper 2007-011416, 2007.

14. Matsumoto A, Moore WR, Lai M-C, Zheng Y, Foster M, Xie X-B, et al. Spray characterization of ethanol gasoline blends and comparison to a CFD model for a gasoline direct injector. SAE technical paper 2010-01-0601, 2010.

15. Mojtabi M, Chadwick N, Wigley G and Helie J. The effect of flash boiling on breakup and atomization in GDI sprays. Como Lake: ILASS, 2008.

16. Schmitz I, Ipp W and Leipertz A. Flash boiling effects on the development of gasoline direct-injection engine sprays. SAE technical paper 2002-01-2661, 2002.

17. Kamoun H, Lamanna G, Weigand B and Steelant J. High-speed shadowgraphy investigations of superheated liquid jet atomisation. In: ILASS Americas 22nd annual conference on liquid atomization and spray systems, Cincinnati, OH, 16-19 May 2010.

18. Oza RD. On the mechanism of flashing injection of initially subcooled fuels. J Fluid Eng 1984; 106(1): 105-109.

19. Oza RD and Sinnamon JF. An experimental and analytical study of flash-boiling fuel injection. SAE technical paper 830590, 1983.

20. Sher E, Bar-Kohany T and Rashkovan A. Flash-boiling atomization. Prog Energ Combust 2008; 34(4): 417-439.

21. Platt U. Physik der Atmosphäre. Heidelberg: Vorlesungsskriptum Universität Heidelberg, 2014.

22. Escobar-Vargas S, Fabris D, Gonzales JE, Sharma R, Bash $\mathrm{C}$, et al. Bubble growth characterization during fast boiling in an enclosed geometry. Int $J$ Heat Mass Tran 2009; 52(21-22): 5102-5112.

23. Rothenwöhrer M. Einfluss thermodynamisch metastabiler Zustände auf den Zerfall und das Mischverhalten von Flüssigkeitsstrahlen. PhD Dissertation, Fakultät für Maschinenwesen, Technische Universität München, Munich, 2003.

24. Karami R, Ashgriz N and Tran HN. The effect of flashing on characteristics of sprays of splash-plate nozzles. In: ILASS Americas 22nd annual conference on liquid atomization and spray systems, Cincinnati, OH, 16-19 May 2010.
25. Ashgriz N. Handbook of atomization and sprays: theory and applications. New York: Springer Science + Business Media, 2011.

26. Miyatake O, Tanaka I and Lior N. A simple universal equation for bubble growth in pure liquids and binary solutions with a non-volatile solute. Int J Heat Mass Tran 1997; 40(7): 1577-1584.

27. Plesset MS and Prosperetti A. Bubble dynamics and cavitation. Annu Rev Fluid Mech 1977; 9(1): 145-185.

28. Fath A. Charakterisierung des Strahlaufbruch-Prozesses bei der instationären Druckzerstäubung. PhD Dissertation, Technische Fakultät, Universität Erlangen-Nürnberg, Erlangen, 1997.

29. Zuo B, Gomes AM and Rutland CJ. Studies of superheated fuel spray structures and vaporization in GDI engines. In: Eleventh international multidimensional engine modeling user's group meeting, 2000, https://www.erc.wisc.edu/documents/Baifang-Zuo-paper.pdf

30. Dondè R, Brunello G, Araneo L and Coghe A. Effect of fuel temperature on the mixing properties of a GDI spray. In: Open meeting on combustion, 23rd event of the Italian section of the combustion institute, Ischia, 22-25 May 2000.

31. Araneo L, Brunello G, Coghe A and Dondé R. Effects of fuel temperature and ambient pressure on a GDI swirled injector spray. SAE technical paper 2000-01-1901, 2000.

32. Schmitz I and Leipertz A. Comparison of the flash boiling influence on the spray structure of a high pressure swirl injector and of a multihole injector for GDI engines. Kyoto, Japan: ICLASS, 2006.

33. Zeng W, Xu M, Wang Z and Hung D. Droplet size characterization of flash-boiling sprays using simultaneous LIEF/MIE techniques and dimensionless analysis. In: ILASS Americas 25th annual conference on liquid atomization and spray systems, Pittsburgh, PA, 5-8 May 2013.

34. Kim YK, Iwai N, Suto H and Tsuruga T. Improvement of alcohol engine performance by flash boiling injection. Tokyo, Japan: Society of Automotive Engineers of Japan, 1980.

35. Boer C, De Bonar G, Sasaki S and Shetty S. Application of supercritical gasoline injection to a direct injection spark ignition engine for particulate reduction. SAE Technical Paper 2013-01-0257, 2013.

36. Analysenzertifikat 114.213:2012. Ottokraftstoff, Qualitätsniveau Super (PetroLab GmbH).

37. Analysenzertifikat 167547:2011. CEC Legislative Fuel RF-02-08 (Haltermann GmbH).

38. Analysenzertifikat 67.505:2006. Ottokraftstoff, Qualitätsniveau Super (PetroLab GmbH).

39. Zigan L. Laserdiagnostische und numerische Untersuchungen zum Einfluss der Kraftstoffzusammensetzung auf die Sprayausbildung bei der Benzindirekteinspritzung. PhD Dissertation, Technische Fakultät, Universität ErlangenNürnberg, Erlangen, 2011.

40. Senda J, Wada Y, Kawano D and Fujimoto H. Improvement of combustion and emissions in diesel engines by means of enhanced mixture formation based on flash boiling of mixed fuel. Int J Engine Res 2007; 9(1): 15-27.

41. Keller P, Knorsch T, Wensing M and Hasse C. Experimental and numerical analysis of iso-octane/ethanol sprays under gasoline engine conditions. Int $J$ Heat Mass Tran 2015; 84: 497-510. 
42. Knorsch T, Heldmann M, Zigan L, Wensing M and Leipertz A. On the role of physiochemical properties on evaporation behavior of DISI biofuel sprays. Exp Fluids 2013; 54(6): 1-14.

43. Lerch J. Analyse der Partikelbildung in direkteinspritzenden hubraumverkleinerten Ottomotoren. PhD Dissertation, Technische Fakultät, Universität Erlangen-Nürnberg, Erlangen, 2013.

44. Lenz M. Experimentelle Untersuchung von Mehrlochinjektoren in einem Ottomotor mit Direkteinspritzung. Dissertation, Technische Fakultät, Universität ErlangenNürnberg, Erlangen, 2010.

45. Khan MM, Helie J, Gorokhovski M, Wood A, Wigley G and Kashdan JT. Numerical analysis of multihole gasoline direct injection sprays. Heidelberg: ICLASS, 2012.

46. Xu M, Zhang Y, Zeng W, Zhang G and Zhang M. Flash boiling: easy and better way to generate ideal sprays than high injection pressure. SAE Int J Fuel Lubr 2013; 6(1): 137-148.

47. Zhang M, Xu M, Zhang Y and Zeng W. Effects of superheat degree on flow field of multi-hole fuel sprays. Heidelberg: ICLASS, 2012.

48. Heldmann M, Knorsch T, Schmitz I, Wensing M and Leipertz A. Investigation of significant spray rotation phenomena under flash-boiling conditions studied on a multihole DISI injector for bio-ethanol E85 and gasoline E5. Estoril: ILASS, 2011.

49. Krämer M, Kull E, Heldmann M and Wensing M. Investigations on gasoline spray propagation behaviour characteristic for multihole injectors. SAE technical paper 2014-01-2732, 2014.

50. Parrish SE and Zink RJ. Spray characteristics of multihole injectors under flash boiling conditions. In: ILASS Americas 21st annual conference on liquid atomization and spray systems, Orlando, FL, May, 2008.

51. Mojtabi M. Optical analysis of multi-stream GDI sprays under various engine operating conditions. PhD Dissertation, Loughborough University, Loughborough, 2011.

52. Hermann A. Modellbildung für die 3D-Simulation der Gemischbildung und Verbrennung in Ottomotoren mit Benzin-Direkteinspritzung. $\mathrm{PhD}$ Dissertation, Fakultät für Maschinenbau, Universität Karlsruhe, Karlsruhe, 2008.

\section{Appendix I}

\section{Notation}

$\mathrm{p}_{\mathrm{a}} \quad$ ambient gas pressure

$\mathrm{p}_{\text {fuel injection pressure }}$

PN particulate number

$\mathrm{p}_{\mathrm{sat}} \quad$ saturation pressure/vapor pressure

$\mathrm{T}_{\mathrm{a}} \quad$ ambient gas temperature

$\mathrm{t}_{\text {det }} \quad$ detection time

$\mathrm{T}_{\text {fuel }} \quad$ fuel temperature

$\mathrm{T}_{\text {sat }} \quad$ saturation temperature 